\title{
Development and Validation of a Scale to Measure Anomie of Students
}

\author{
Hilal Bashir ${ }^{1} \cdot$ Ranjan Bala ${ }^{1}$
}

Received: 18 August 2017/ Accepted: 13 November 2018/Published online: 3 December 2018

(C) National Academy of Psychology (NAOP) India 2018

\begin{abstract}
The goal of the present study was to develop and validate a measurement of anomie within the Indian context. A scale development approach was used to achieve it. To produce the items, their refinement and validation, this study has adopted well-accepted and renowned scale development procedures. Two independent data sets were used to evaluate the structure of the scale. The findings of this study present a 21 -item three-factor scale measuring anomie of Indian students. Moreover, anomie scale has an adequate internal consistency coefficient, which is " $\alpha=.89$." This study is the foremost study, which has developed a reliable and valid scale for measuring the anomie in Indian context.
\end{abstract}

Keywords Anomie scale · Factor analysis .

Meaninglessness · Distrust and moral decline

\section{Introduction}

The conceptualization of anomie originated in sociology by Emile Durkheim who defined it as "breakdown in social structure and moral deterioration." Merton (1962[1957]) extends this thinking that anomie originates from discrepancy between the social aspirations and legitimate means to accomplish these goals. While MacIver (1950) defines psychological anomie as the breakdown of the individual's

Hilal Bashir

hilalbashir14@gmail.com

Ranjan Bala

ranjan.16366@1pu.co.in

1 Department of Education, Lovely Professional University, Jalandhar, India sense of attachment to society, Srole (1956) explores anomie as a psychological state where an individual may feel the complexity of integrating into contemporary society. Moreover, anomie is a set of feelings, attitudes and beliefs in the individual's mind (Davol \& Reimanis, 1959; McClosky \& Schaar, 1965).

Fischer (1973) and Teevan (1975) define anomie differently as a feeling of cynicism (i.e., distrust), powerlessness and social isolation. Travis (1993) synonymized anomie with alienation, and defined it as a psychological state where aspirations are unfulfilled. That is, members of society become alienated if they are placed in marginal situations and if their goals are left unmet. In regard to measuring anomie, he asserts that previous studies primarily focus on the normative structures of society (e.g., class structure) and its effect on persons rather than measuring the attitudinal levels of examination (e.g., attitudes, beliefs and values) that are important in studying anomie. In many cases, anomie has been defined as in terms of dishonest behavior (Bashir \& Singh, 2018).

Anomie is a complex, dynamic concept that refers simultaneously to a social state and an individual state of mind (Bjarnason, 2009). Recently, Teymoori et al. (2016) conceptualize anomie as the shared subjective perception about the state of society surrounding two situations: the breakdown of social structure (i.e., distrust and moral decline) and the breakdown in leadership (i.e., lack of legitimacy and effectiveness). The operationalization of anomie as a state of mind has associated anomie with a tendency of individuals to be self-interested (Konty, 2005), normless (Baumer, 2007; Bjarnason, 2009), isolated and lonely (Fischer, 1973; Martin, 2000; Srole, 1956), having a felt sense of meaningless (Martin, 2000; Thorlindsson \& Bernburg, 2004) and purposelessness or powerlessness (Form, 1975; Bjarnason, 2009). Thus, the construct of 
anomie can be conceptualized as a person's characteristic when the individual believes that there are no rules, social norms and prescriptions, which can control his/her own conduct as well as the actions of other people of the society, and when the individual abides the psychological state of social isolation and meaninglessness (Levina et al., 2015).

\section{Previous Measures of Anomie}

After reviewing the literature of anomie, it was found that several measurements have been developed to investigate anomie. The anomie scale developed by Srole (1956) is most commonly used to examine anomie among individuals. This instrument has been used in numerous studies, and several instruments were based on this measurement like Fischer (1973) and Teevan (1975) which addressed the drawbacks in Srole's scale.

Notwithstanding its deficiency, McClosky and Schaar (1965) proposed psychological anomie based on nine dichotomous (agree/disagree) items to measure an individual's state of mind. It is believed that all statements in the scale measure individual's beliefs, attitudes and feelings. Additionally, Teevan (1975) suggested a modification of the referent in items like "the average man" and "a person" to "I" in order to consistently measure a person's own anomie, rather than the anomie of others or the degree of anomie in society. Moreover, Travis (1993) proposed the margin of society (MOS) alienation scale that consists of fourteen items on Likert format. The scale eliminates the broadness of Srole's scale and attempts to identify attitudinal variables of alienation.

Elmore (1962) proposed comprehensive measure of psychological anomie than the one devised by Srole. According to Elmore, although the Srole scale is adequate as a quick measure of personal concept of anomie, it is limited because it consists of only five items. As it was not subjected to any recognized scale construction procedure, it fails to include any hypothesized facets of anomie mentioned in the theoretical literature; and it seems subject to acquiescent response set. The attention of investigators in anomie as assessed by these instruments appears to turn down at a stable rate. These traditional instruments have numerous practical and theoretical deficiencies and are becoming increasingly out of date (Bjarnason, 2009). Similarly, as we have investigated the extensive literature on anomie in Indian context, no such work has been done in this area. So there is need of time to develop and validate the measurement of anomie.

\section{The Dimensionality of Anomie}

The article of Srole (1956) made the first operationalization of anomie and evaluated anomie with five statements. The operationalization of anomie is faced with controversies among researchers, so is its dimensionality too. Because some researchers viewed the phenomenon as a multi-dimensional concept with three components: Teevan (1975) yielded three components, (1) powerlessness (2) feeling of cynicism, i.e., distrust, and (3) social isolation. Another investigation made by Adnanes (2007) postulated three facets of anomie: one indicates psychological anomie and another two components are normless and nostalgia referring to a person's attitude and feeling about the societal changes. There are some drawbacks in Adnanes's (2007) study: The reliability coefficient of the measure was .59 , whereas internal consistency of alpha for second and third subscale was also found to be low as the value came out to be .36 and .30 , respectively. Another essential drawback is the vagueness of the subscales. The investigator did not elucidate what accurately he signifies by nostalgia and psychological anomie (Heydari, Davoudi, \& Teymoori, 2011).

Nonetheless, investigator like Bjarnason (2009) designed the anomie scale in a two-dimensional construct namely, (1) exteriority and (2) constraint. Exteriority refers to experiencing the social world as an objective, predictable reality that follows a deductive reason, while constraint refers to the extent to which one experiences personal commitment to the expectation and demands of society (Heydari et al., 2011). In addition, Heydari et al. (2011) developed feeling of anomie scale as three-dimensional constructs: (1) powerlessness (2) meaninglessness and distrust and (3) fetishism of money. Heydari et al. (2011) categorizes meaninglessness and distrust as a sole facet. This single classification runs contrary to the previous research studies, where meaninglessness (Dean, 1961; Travis, 1993; Smith \& Bohm, 2008) and distrust, i.e., (McClosky \& Schaar, 1965; Sampson \& Bartusch, 1998), are characteristically seen as two different constructs. The logic for this dimensionality is unclear (Yang, 2015).

Another research study conducted by Yang (2015) asserts that anomie is a two-dimensional construct comprising of (1) meaninglessness and (2) cynicism. Moreover, Teymoori et al. (2016) elaborate anomie as two-dimensional construct, i.e., breakdown of social structure (moral decline and lack of trust) and breakdown of leadership (effectiveness and legitimacy). Intensive investigation on anomie literature was conducted and found that anomie is comprehensive and encompassing constructs of alienation, powerlessness and confusion about rules (McClosky \& Schaar, 1965; Fischer, 1973; Martin, 2000; Thorlindsson \& Bernburg, 2004). The present investigation contributes 
revisiting the construct and develops a scale that measures simultaneously a social state and an individual state of mind. Therefore, the main objective of this study is to develop the psychometric properties of the refined anomie scale in Indian context and determine its dimensionality.

\section{Method}

A scale development study was used to develop an instrument that sufficiently measures the feeling or perception of anomie. The procedures were as follows: (a) defining and specifying the construct being measured, (b) generating an item pool, (c) providing and considering the study of experts on initial item pool, (d) refining and validating scale, and (e) evaluating the items (DeVellis, 2016; Netemeyer, Bearden, \& Sharma, 2003; Wymer \& Alves, 2012). Moreover, details related to participants, instrument and procedures and data analysis can be seen in detail below.

\section{Participants}

The population of the current research is undergraduate university students of Jammu and Kashmir. The participants in this research were 900 undergraduate university students in Kashmir division of Jammu and Kashmir. Two independent data sets were used to evaluate the structure of the anomie scale. In the first phase, 450 (240 male and 210 female) students participated and exploratory factor analysis (EFA) was performed to evaluate the structure of the scale. In the second phase, 450 (227 male and 223 female) students participated and confirmatory factor analysis (CFA) was performed to confirm the factors. The age range of participants was 17-23 years. Initially, out of three divisions in Jammu and Kashmir, one division was selected randomly and students were chosen conveniently as participants. The sample size is adequate as per the researchers Hair, Black, Babin, and Anderson (2010) for exploratory factor analysis and confirmatory factor analysis.

\section{Instrument and Procedures}

In this investigation, rigorous literature was studied in order to develop a valid and reliable scale. In initial stage, item generation was based on our conceptual model and we adapted items from previous scales. The study adapted a measure of anomie developed by Srole (1956), Elmore (1962), Teevan (1975), McClosky and Schaar (1965), Rushing (1971), Travis (1993), Tsahuridu (2011), Bjarnason (2009) and Teymoori et al. (2016). Initially, 49 statements were constructed, 34 items were adapted from prior measures, and more 15 statements were constructed by the investigators. However, since most statements' wordings were adapted to be more appropriate in the perspective of the current study, summated evaluation method proposed by Likert (1932) has been used for developing the present scale. Therefore, the scoring method of the present 5-point Likert scale is: Strongly agree $=5$, Agree $=4$, Neutral $=3$, Disagree $=2$ and Strongly disagree $=1$, whereas negative statements are coded as vice versa. The total calculated score would indicate level of perception of anomie among students. So, higher score on anomie measurement interprets that students have higher perception of anomie and vice versa.

\section{Content Validity}

After preparing the scale items, the content validity was performed qualitatively and quantitatively with the involvement of sixteen experts who hold doctorates in the field of sociology, education and psychology. For qualitative analysis, 49 statements were formulated and the entire group of statements was submitted to content experts, which included both anomie scale and instructions to assess content and organization of measurement.

An outline of qualitative assessment criteria as recommended by McKenzie, Wood, Kotecki, Clark, and Brey (1999) was used, and proper modifications were made to improve the overall quality of the scale. After completion of revisions of the qualitative reviews, a quantitative assessment packet was submitted to each expert. An assessment tool consisting of three items was used in order to analyze the expert viewpoints. Experts were asked to rate the appropriateness of each item by stating if each item was "Suitable," "Must be corrected," or "Not suitable." By combining all the assessment tools as one assessment tool, the issue of how many experts approved each possible option of the items was determined. In this perspective, the content validity of the statements was determined with the "(The number of the experts who answered positively/The number of total experts) - 1" formula for each item (Veneziano \& Hooper, 1997). However, minimum values of content value ratio (CVR) at $\alpha=.05$ significance level are included for an expert opinion according to Veneziano and Hooper (1997). Quantitative expert view was analyzed, 13 statements were deleted, and further 35 items were retained to perform the exploratory factor analysis. When interpreted according to the table given by Veneziano and Hooper (1997), sixteen expert opinions are used in the content validity calculations of the anomie scale used in this study; therefore, to provide significance statistically according to expert numbers, for 16 experts .42 value was used as the content validity criterion (CVC). However, retained items obtained CVR value above .93 in this 
assessment. Moreover, items having CVR values below .42 were excluded from the final scale.

\section{Analysis}

In order to test the factorial validity of the anomie scale, it was applied to four hundred and fifty undergraduate university students, who were sample of the study. The Kaiser-Meyer Olkin (KMO) coefficient was administered to determine whether the sampling size was appropriate for factorization or not, and the Bartlett Test of Sphericity was applied to determine whether or not the data were from multivariate normal distribution. For the factorial validity, the factorial structure of the scale was determined by using the explanatory factor analysis (EFA). The explanatory factor analysis is applied to determine the association between the unknown latent variables and the observed variables (Schreiber, Nora, Stage, Barlow, \& King, 2006). As a matter of fact, it is expected in factor analysis, which is performed to locate the variable in the factor group in question, that the factor loadings are high. When the literature is scanned, it is observed that there is a widely held belief that an item must have at least .30 minimum size for the factor loadings of the relevant item. According to Tabachnick and Fidell (1996), the loading value of each variable must be evaluated at or over .32 as a basic rule.

The analysis of the data was conducted using exploratory factor analysis (EFA) in IBM SPSS statistical software version-22. The EFA procedure uses principal components analysis (PCA) with varimax method. To determine the number of factors, we look at the Kaiser-Meyer-Olkin measure of sampling adequacy and Bartlett Test of Sphericity. Several iterative cycles of factor analysis were conducted on the data set. The total variance explained and numbers of factors extracted were examined after each iteration. Factors with low communalities and no correlation were deleted with the aim of improving the factor structure to get a matrix with much clear loadings. The Kaiser-Meyer-Olkin (KMO) measure of sampling adequacy was found to be .92 . (The minimum acceptable coefficient is .60 (Tabachnick \& Fidell, 1996), and the Bartlett test of Sphericity was significant 4598.445, $p<.001$.) Both of these suggest adequacy of the participants for exploratory factor analysis. Since the values obtained as a result of the above-mentioned analyses fit the basic hypotheses at a good level, it was decided that the factor analysis could be conducted (Kothari \& Garg, 2014).

Subsequently, the factor loads show the correlation between the item to be measured and the main structure; the relevant dimensions that appeared as a result of the basic component analysis and the factor loadings were examined. After these processes, the last form of the anomie scale had 22 items. The rotated components matrix, which was converted with varimax method, and which was obtained as a result of the factor analysis, is given in Table 1. The varimax method, which is one of the vertical rotating methods, was preferred in order to ensure that the factor variances would have high value with a few variables. Exploratory factor analysis revealed a three-facet structure, explaining $56.91 \%$ of the variance (acceptance variance is 50\%; Streiner, 1994), and all items had loading above .40. (Acceptable item loading of sample 350 is .40 , Hair et al., 2010.) We named each factor based on the association between items and the relevant literature (Bashir \& Bala, 2018). The first factor consisted of items associated with meaninglessness (9 items), second factor consisted of items associated with distrust (8 items), and third factor consisted of the items associated with moral decline (5 items). The results of the factor analysis and origin of items of anomie scale are presented in Table 1.

\section{Confirmatory Factor Analysis}

According to Joreskog and Sorbom (2004), confirmatory factor analysis (CFA) is a distinct case of structural equation modeling which is also known as linear structural relationship model. Even though exploratory factor analysis gives an idea of dimensionality, CFA, as the name implies, basically focuses on whether a hypothesized factor model does or does not fit the data set. Thus, CFA is now a universally accepted technique to confirm dimensionality (Floyd \& Widaman, 1995; Netemeyer et al., 2003). The CFA was applied using IBM-SPSS Amos 19 version to three factors extracted in EFA. The structure of the anomie scale, which consisted of 22 items and three factors, was tested by using the confirmatory factor analysis. This analysis was made over 450 students, who were selected conveniently. Subsequently, a series of improved run of CFA was carried on, the results of statistics for fit indices improved with every step, and final result came to moderate fit as- $\chi^{2}=489.449, \mathrm{DF}=172, p=.001$, root mean square of approximation $(\mathrm{RMSEA})=.064, \mathrm{CMIN} / \mathrm{DF}=$ 2.846 , GFI $=.902$, AGFI $=.869, \mathrm{CFI}=.914$. Nonetheless, researcher like Schumacker and Lomax (2016) suggested that if majority of the fit indices are at or over threshold value, then it can be conclude that theoretical model is supported by the data. As a result, all the standard fit indices show that the factor structure of the model is approved. In this analysis, item number 6 was deleted to improve the model fit. The final scale consisted of 21 items and three dimensions scale. Figure 1 provides a holistic view of the confirmatory factor analysis model. 
Table 1 Results of the factor analysis of the anomie scale (AS)

\begin{tabular}{|c|c|c|}
\hline S. no & Items & $\begin{array}{l}\text { Factor } \\
\text { loadings }\end{array}$ \\
\hline $\begin{array}{c}\text { Factor: } \\
\text { one }\end{array}$ & Meaninglessness (ML) & \\
\hline Item7 & I think the life of an ordinary man is getting worse day by day. (Srole, 1956) & .741 \\
\hline Item 25 & I think there are no clear rules in recruitment of jobs. (Author made) & .730 \\
\hline Item 2 & I think a person's future is determined by higher officials. (Author made) & .711 \\
\hline Item26 & I have no control over my destiny. (Teevan, 1975) & .709 \\
\hline Item 22 & I really do not know what to do with my life. (Teevan, 1975) & 668 \\
\hline Item24 & I feel lonely and unrelated to my fellow human beings. (Teevan, 1975) & 643 \\
\hline Item31 & I believe that inspite of one's capability nobody knows what is expected from him/her. (Bjarnason, 2009) & .598 \\
\hline Item06 & I get the feeling that life is worthless. (Teevan, 1975) & .590 \\
\hline Item 08 & I often have trouble deciding which rules to follow. (Travis, 1993) & .569 \\
\hline $\begin{array}{l}\text { Factor: } \\
\text { two }\end{array}$ & Distrust (DT) & \\
\hline Item09 & I believe people are caring with each other*. (Author made) & .801 \\
\hline Item14 & I think public officials do not care about the problems of the common man.(Srole, 1956; Teevan, 1975) & 697 \\
\hline Item11 & I don't know whom I can trust and rely on. (Tsahuridu, 2011; Teymoori et al., 2016) & 685 \\
\hline Item03 & I think people follow whatever rules they want to follow. (Bjarnason 2009) & 682 \\
\hline Item 10 & I think higher administration doesn't care about the careers of unemployed educated youths. (Author made) & 672 \\
\hline Item04 & I like to live by society rules*. (Travis, 1993) & 651 \\
\hline Item 21 & $\begin{array}{l}\text { I think getting higher education is unimportant for future life plan because it does not pay anything in life. (Author } \\
\text { made) }\end{array}$ & .564 \\
\hline Item 15 & If I work hard and study today, I am sure that a job will be open for me later*. (Elmore, 1962) & .447 \\
\hline $\begin{array}{r}\text { Factor: } \\
\text { three }\end{array}$ & Moral decline (MD) & \\
\hline Item 27 & $\begin{array}{l}\text { I think that if something works, it doesn't really matter whether it is right or wrong. (Rushing, 1971; Teymoori et al., } \\
\text { 2016) }\end{array}$ & 630 \\
\hline Item29 & I think that there are no clear moral standards to follow in our society. (Teymoori et al., 2016) & .583 \\
\hline Item28 & $\begin{array}{l}\text { I think that honesty doesn't work all the time; dishonesty is sometimes a better approach to get ahead. (Rushing, 1971; } \\
\text { Teymoori et al., 2016) }\end{array}$ & .552 \\
\hline Item13 & I think a person is justified in doing anything if the reward is high enough. (Rushing, 1971; Teymoori et al., 2016) & .485 \\
\hline Item 12 & I obey the laws no matter how much it interferes with my personal ambitions*. (Rushing, 1971) & .439 \\
\hline
\end{tabular}

*Indicates negative items

\section{Reliability Analysis}

The reliability was measured by interpreting the obtained value of Cronbach's alpha (Cronbach, 1951) to assess the internal consistency of the scale. So, the Cronbach's alpha for the meaninglessness was found out to be ".89," distrust “.81," moral decline ".72" and anomie scale, " $\alpha=.89$." This illustrates a high degree of internal consistency as interpretation made by DeVellis (2016) for the interpretation of alpha indicated that value above .7 is acceptable. So, our reliability analysis suggests that anomie scale exhibits high degree of internal consistency.

\section{Construct Validity of Anomie Scale}

The construct reliability (CR) of anomie scale is satisfactory as per the researcher, i.e., .70 (Hair et al., 2010). A sufficient criterion is obtained for construct reliability (CR) with the meaninglessness factor of .89 , distrust of .89 and moral decline of .83 . Based on the construct reliability (CR) values, each factor has adequate convergent validity as the average variance extracted (AVE) values are near about .50. (Acceptable threshold limit of AVE is .50 or greater; Hair et al., 2010.) In the present research study, the discriminant validity was evaluated by using the pattern method (Fornell \& Larcker, 1981), which states that, "discriminant validity exists when Squared Inter construct correlation (SIC) is less than average variance extracted (AVE)." For this purpose, square inter constructs correlation (SIC) is less than the AVE which indicates good discriminant validity. Hence, the constructs are truly distinct from others. Therefore, these aspects reflect the construct validity of the scale. On the other hand, the factor loadings 


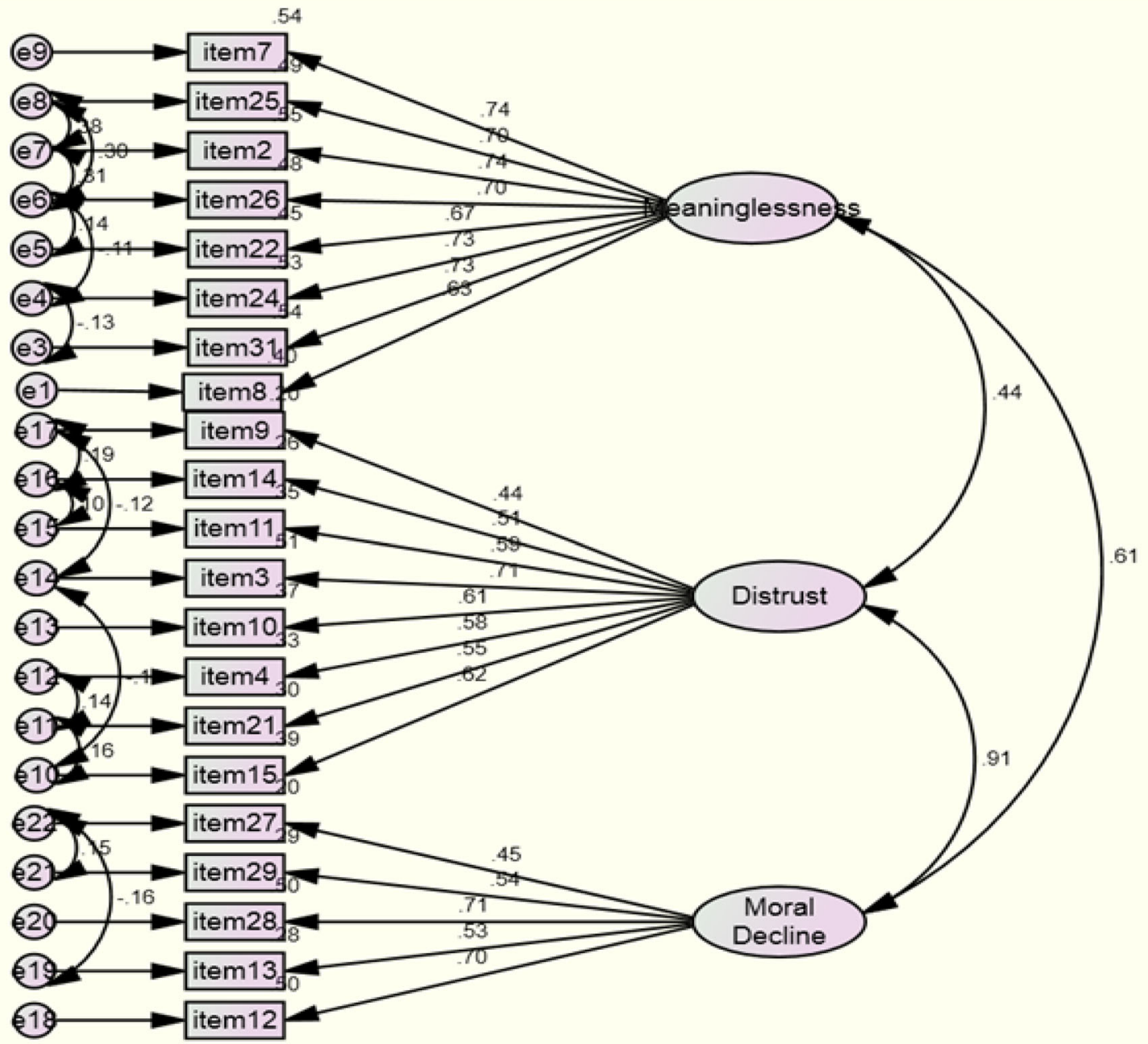

Fig. 1 Confirmatory factor analysis model of anomie scale

and reliability measures also provide strong evidence for the construct validity.

\section{Discussion}

The purpose of the present study was to develop and validate a measure which could adequately fulfill the psychometric properties of the anomie scale. A painstaking methodological procedure was carried out to develop and validate measurement of anomie based on qualitative evaluation (Netemeyer et al., 2003; DeVellis, 2016; Wymer \& Alves, 2012). In initial stage, 49 statements were formulated and the entire group of statements was submitted to judges with a request to suggest any ambiguity, vagueness or dual meaning coming from any statement. Moreover, expert view was analyzed, 13 statements were deleted, and further 35 items were retained to perform the exploratory factor analysis. Analysis using EFA for anomie scale was performed, and Kaiser-Meyer-Olkin (KMO) measure of sampling adequacy was found to be .92 . (The minimum acceptable coefficient is .60; Tabachnick \& Fidell, 1996.) On the other hand, Bartlett Test of Sphericity produces a $p$ value $<.01$ for this scale. Both of these suggest adequacy of the participants for exploratory factor analysis.

The scale passed all criteria like reliability, factorial validity, structural validity and construct validity. For instance, the scale not only has adequate statistical buttress but has ample theoretical support too. The factors which are extracted through EFA and confirmed through CFA have also similar references in empirical studies too. The first factor/domain is meaninglessness which refers to the feeling of a person in the face of social and personal disintegration, life is not worth living (Heydari et al., 2011; Yang, 2015; Levina et al., 2015); second factor is distrust which refers to the feeling of cynicism (i.e., distrust) or a perception that society's social fabric is breaking down, 
including a perceived lack of trust (Teevan, 1975; Heydari et al., 2011; Yang, 2015); and the last factor is moral decline which refers to the perception that society's social fabric is breaking down, including moral standards (Teymoori et al., 2016). The results of the scale development study are consistent with theoretical investigation about anomie construct.

This study systematically contributes to the existing literature on anomie. Investigators in each phase of scale development have used different samples to test and validate the developed model, with strong empirical evidence of robustness of the model. The developed scale can be beneficial to measure the anomie of students in today's changing and turbulent environments. Therefore, the results of this study provide an absolute coverage and understanding of various touch points used in measuring anomie. The concentration of this investigation to highlight anomie in the university/college campus moves practice closer to addressing individual and societal changes with a common frame. In addition, with regard to the need of investigation about anomie in Indian context, a suitable tool would be handed over to Indian researchers. Because in India, a host of societal and social problems are escalating, some of them to have sprung up recently while some pre-existing ones have started worsening. These problems are worth being viewed from the anomie lens (Thiel, 2011).

The practical contribution of the research is that it, first, confirms the existence of anomie multi-dimensional construct in the academic environment. Concentrating on anomie's work, this study advances anomie by validating multi-dimensional construct in an academic setting. The survey developed for the study is a new way of measuring anomie in the Indian context. The study provides an instrument with which to measure normlessness in the academic context and a way of thinking about the academic environment as a series of reciprocal and supportive conversations. The good news is that by painstakingly understanding anomie the study is that much closer to understanding an academic environment where the norms in place have a strong moral underpinning that create a sense of connection, cohesion and even harmony in the academic setting.

The research shows indications of academic anomie, a variation of societal anomie. Academic anomie has its own distinct characteristics, but is clearly representative of anomie construct. The instrument could point to the similarity and differences of academic institutions. Because the body of scholarly work on anomie in the academic workplace is small and exists over time in numerous fields of study, it has been difficult to understand at its scholarly center. The another practical contribution of this study to anomie theory is the collection and organization, in a single reference source, comprehensive scholarly literature on anomie in the academic workplace, producing a repository for others to easily locate and utilize what is known about anomie in the academic context. Finally, the evidence of this measurement suggests that this scale has robust psychometric properties to measure anomie in Indian context. In particular, administering the measure to undergraduate students at universities might lead program developers, curriculum framers, educationalists, administrators and policy-makers to determine most epidemic factors of anomie and take indispensable measures consequently. Furthermore, the tool can be used to examine the consequences of anomie which can help policy-makers to identify the most important reasons behind low psychological well-being and life satisfaction of students.

\section{Conclusion}

The present investigation contributes to revisiting the anomie construct and develops a scale that measures simultaneously a social state and an individual state of mind. The results confirmed anomie scale as a highly reliable and valid instrument. The findings of this study present a 21-item three-factor scale, i.e., meaninglessness, distrust and moral decline measuring anomie of Indian students. In addition, findings revealed that the present measure adequately possesses psychometric properties. Therefore, this study is the foremost study, which has developed a reliable and valid scale for measuring the anomie in Indian context.

The present scale is administrable on undergraduate university students in academic context, to assess their anomie in today's changing and turbulent environment or present age of competitions where students can feel frustration, anxiety, despair, hopelessness and discouragement. Moreover, the current measurement can be employed on students to assess their adjustment with environment. Using this measure will capture a snapshot of the perception of meaninglessness of life, students' trust on higher authority or society and norms of a population by measuring the absence or presence of specific normative facets of the academic context. Furthermore, its usability would be in academic sector where students' education is a means to achieve their goal (employment or job attainment). In the educational institutions, they are trained for years together but when they realize about their future during their academic career they may feel unsatisfied, isolated and distrusted because of unemployment or unavailability of suitable employment. Additionally, it will provide insight into the general attitude of the participants, moral state of the individual and the generally patterned social arrangements. 


\section{Limitations and Future Research}

Although the study was able to effectively answer the research objectives, there were some evident limitations. First, surveying only undergraduate students created a homogeneous perspective of academic anomie. The study could have involved other student populations such as postgraduate students, research scholars and senior secondary school students. Second, surveying undergraduate students from only one province of Jammu and Kashmir limited the generalizability of the results. Having undergraduate students participate from other institutions would have shown the generalizability of the results. The study assumes that Durkheim's theory of anomie effectively explains anomie in the academic context. Even if true, other anomie theories may be just as viable. The authors did not establish divergent validity, and this is one of the limitations of the present study. Therefore, this study suggests that another instrument should be used to establish the divergent validity as well as convergent validity of anomie scale.

Constructing a new instrument to measure anomie in the academics provides numerous opportunities for future research. First, the survey can be tested with other populations to look for norms as well as levels of anomie. Second, the survey can be modified to reflect other academic types. This might include government, private or theological settings. Third, the instrument helps point to practical interventions that can address anomie in the academic context. Using the instrument to measure preand post-intervention anomie is a natural next step in the research of academic anomie. Fourth, extensive phenomenological study should be conducted based on this instrument to expose the reasons behind this phenomenon among different cultures. Fifth, the findings provide support for conducting further psychometric examination on the anomie scale (AS). Scaling items should be revised, added, modified and deleted to improve consistency/reliability of the subscales of anomie to ensure that a similar number of statements are assessing each of the components. Sixth, a further research can be conducted to determine the relationship of anomie with socioeconomic status as well as corruption and unemployment in the societies. Seventh, researchers should collect additional data set for this measure to reconfirm the structural and discriminant validity of anomie scale because our analysis suggested that CFA model is moderately fit. More attempts at refinement of procedures for measuring anomie are definitely in order. More research is needed to understand and respond to the multitude of value orientations among college age youth particularly among cultural minorities. Finally, this study suggests that follow-up investigation with this instrument should be conducted in various countries to get an image of anomie in India in requisites of the perception of anomie all along leading to such illegal or deviant behavior.

\section{References}

Adnanes, M. (2007). Social transitions and anomie among postcommunist Bulgarian youth. Young, 15(1), 49-69.

Bashir, H., \& Bala, R. (2018). Development and validation of Academic Dishonesty Scale (ADS): Presenting a multidimensional scale. International Journal of Instruction, 11(2), 57-74.

Bashir, H., \& Singh, K. (2018). The investigation of the relationship between anomie and academic dishonesty of college students. IAHRW International Journal of Social Sciences Review, 9(1), 5-8.

Baumer, E. P. (2007). Untangling research puzzles in Merton's multilevel anomie theory. Theoretical Criminology, 11(1), 63-93.

Bjarnason, T. (2009). Anomie among European adolescents: Conceptual and empirical clarification of a multilevel sociological concept. Sociological Forum, 24(1), 135-161.

Cronbach, L. J. (1951). Coefficient alpha and the internal structure of tests. Psychometrika, 16(3), 297-334.

Davol, S. H., \& Reimanis, G. (1959). The role of anomie as a psychological concept. Journal of Individual Psychology, 15(2), 215-225.

Dean, D. (1961). Alienation: Its meaning and measurement. American Sociological Review, 26(5), 753-758.

DeVellis, R. F. (2016). Scale development: Theory and applications (2nd ed.). London: Sage publications.

Elmore, T. M. (1962). The development of a scale to measure psychological anomie. (Doctoral Thesis), Ohio State University, Columbus, Ohio, USA.

Fischer, C. S. (1973). On urban alienations and anomie: Powerlessness and social isolation. American Sociological Review, 38(3), 311-326.

Floyd, F. J., \& Widaman, K. F. (1995). Factor analysis in the development and refinement of clinical assessment instruments. Psychological Assessment, 7(3), 286-299.

Form, W. H. (1975). The social construction of anomie: A four-nation study of industrial workers. American Journal of Sociology, 80(5), 1165-1191.

Fornell, C., \& Larcker, D. F. (1981). Evaluating structural equation models with unobservable variables and measurement error. Journal of Marketing Research, 18(1), 39-50.

Hair, J. F. J., Black, W. C., Babin, B. J., \& Anderson, R. E. (2010). Multivariate data analysis (7th ed.). Upper Saddle River, NJ: Prentice Hall Inc.

Heydari, A., Davoudi, I., \& Teymoori, A. (2011). Revising the assessment of feeling of anomie: Presenting a multidimensional scale. Procedia-Social and Behavioral Sciences, 30, 1086-1090.

Joreskog, K. G., \& Sorbom, D. (2004). LISREL 8.7. Chicago: Scientific Software International Inc.

Kothari, C. R., \& Garg, G. (2014). Research methodology: Methods and techniques (3rd edition). New Delhi: New Age International (P) Limited.

Konty, M. (2005). Microanomie: The cognitive foundations of the relationship between anomie and deviance. Criminology, 43(1), 107-131.

Levina, J., Mārtinsone, K., \& Kamerāde, D. (2015). Sex and age differences in levels of anomia of latvian inhabitants. Society. 
Integration. Education. Proceedings of the International Scientific Conference, Vol. 3 (pp. 567-576). Rēzekne: RA izdevniecība. https://doi.org/10.17770/sie2015vol3.475.

Likert, R. A. (1932). A technique for the measurement of attitudes. Archives of Psychology, 22(140), 5-55.

MacIver, R. M. (1950). The ramparts weguard. New York: Macmillan.

Martin, R. (2000). Anomie, spirituality, and crime. Journal of Contemporary Criminal Justice, 16(1), 75-98.

McClosky, H., \& Schaar, J. H. (1965). Psychological dimensions of anomy. American Sociological Review, 30(1), 14-40.

McKenzie, J. F., Wood, M. L., Kotecki, J. E., Clark, J. K., \& Brey, R. A. (1999). Establishing content validity: Using qualitative and quantitative steps. American Journal of Health Behavior, 23(4), 311-318.

Merton, R. K. (1962 [1957]). Social theory and social structure, Glencoe, Illinois: Free Press.

Netemeyer, R. G., Bearden, W. O., \& Sharma, S. (2003). Scaling procedures: Issues and applications. London: Sage Publications.

Rushing, W. A. (1971). Class, culture and social structure and anomie. The American Journal of Sociology, 76(5), 857-872.

Sampson, R. J., \& Bartusch, D. J. (1998). Legal cynicism and (subcultural?) tolerance of deviance: The neighborhood context of racial differences. Law and Society Review, 32(4), 777-804.

Schreiber, J. B., Nora, A., Stage, F. K., Barlow, E. A., \& King, J. (2006). Reporting structural equation modeling and confirmatory factor analysis results: A review. The Journal of Educational Research, 99(6), 323-338.

Schumacker, R. E., \& Lomax, R. G. (2016). A beginner's guide to structural equation modeling (4th ed.). New York: Routledge.

Smith, H., \& Bohm, R. (2008). Beyond anomie: Alienation and crime. Critical Criminology, 16(1), 1-15.
Srole, L. (1956). Social integration and certain corollaries: An exploratory study. American Sociological Review, 21(6), 709-716.

Streiner, D. L. (1994). Figuring out factors: The use and misuse of factor analysis. Canadian Journal of Psychiatry, 39(3), 135-140.

Tabachnick, B. G., \& Fidell, L. S. (1996). Using multivariate statistics (3rd ed.). New York, NY: Harper Collins College.

Teevan, J. J., Jr. (1975). On measuring anomia: Suggested modification of the Srole scale. The Pacific Sociological Review, 18(2), 159-170.

Teymoori, A., Jetten, J., Bastian, B., Ariyanto, A., Autin, F., Ayub, N., et al. (2016). Revisiting the measurement of anomie. PLoS ONE, 11(7), 1-27.

Thiel, S. (2011). Global anomie and India: A conceptual approach source. Indian Journal of Asian Affairs, 24(1/2), 17-34.

Thorlindsson, T., \& Bernburg, J. G. (2004). Durkheim's theory of social order and deviance: A multi-level test. European Sociological Review, 20(4), 271-285.

Travis, R. (1993). The MOS alienation scale: An alternative to Srole's anomia scale. Social Indicator Research, 28(1), 71-91.

Tsahuridu, E. E. (2011). An exploration of factors affecting work anomia. Journal of Business Ethics, 99(2), 297-305.

Veneziano, L., \& Hooper, J. (1997). A method for quantifying content validity of health-related questionnaires. American Journal of Health Behavior, 21(1), 67-70.

Wymer, W., \& Alves, H. M. B. (2012). Scale development research in nonprofit management and marketing: A content analysis and recommendation for best practices. International Review on Public and Nonprofit Marketing, 10(1), 65-86.

Yang, A. (2015). Quantifying anomia: Development of a scale. (Master's Dissertation). College of Science and Mathematics, California State University, Fresno, USA. 